\title{
A life-cycle cost analysis of resilient flooring materials in acute-care facilities
}

\author{
Deborah Wingler* \\ Healing Design Integration, Clemson, United States
}

Received: July 10, 2018

DOI: $10.5430 /$ jha.v7n5p70
Accepted: August 28, $2018 \quad$ Online Published: October 9, 2018

URL: https://doi.org/10.5430/jha.v7n5p70

\begin{abstract}
Objective: This study compares the impact of maintenance protocols on coated and non-coated resilient flooring materials over the building life of an acute-care facility. The purpose of this study is to provide healthcare administrators, facility managers and designers with evidence regarding the total cost of ownership of different resilient flooring materials.

Methods: Utilizing a life-cycle costing analysis (LCCA), a two-phase economic evaluation was conducted using both industry and real-time data collected from four health systems across three distinct geographic regions in the U.S. to evaluate the impact of coated and non-coated resilient flooring materials over the usable life of an acute-care facility.

Results: Findings from both the first and second phase LCCA suggest that maintenance protocols can have a substantive impact on the total cost of ownership for resilient flooring materials due to the increase in operations and maintenance costs associated with a coated maintenance protocol. The point in time at which the factory applied finish failed for a non-coated flooring material was also shown to greatly contribute to the total cost of ownership.

Conclusions: The use of real-time data, coupled with a systematic evaluation provided contextual information that proved essential to understanding some of the intricacies involved in resilient flooring maintenance protocols that can greatly influence economic outcomes. This approach supports an evidence-based decision making process for healthcare executives and environmental services staff to not only effectively evaluate new resilient flooring material selections, but to also proactively evaluate current maintenance protocols for increased monetary savings.
\end{abstract}

Key Words: Life-cycle cost analysis, Resilient flooring materials, Healthcare, Acute-care facilities, Environmental services, Facility management, Floor maintenance

\section{INTRODUCTION}

Flooring is a critical capital investment decision for healthcare facilities. When making this crucial design decision, long-term cost-effectiveness of a resilient flooring material is often overlooked for lower initial costs, leaving healthcare organizations exposed to increased future cost obligations. ${ }^{[1]}$ Over the usable life of a healthcare facility, frequently scheduled cleaning and maintenance protocols due to heavy foot and equipment traffic, along with frequent replacement and repair, can account for a considerable portion of the total cost of ownership. ${ }^{[2]}$ Resilient flooring continues to be a dominant material choice for healthcare facilities due to technological advances in material science that support a wide range of material compositions, finishes, and aesthetic alternatives, with varying manufacturer recommended maintenance regimes and cost structures for each material. ${ }^{[3]}$ This study compares the impact of maintenance protocols on coated and non-coated resilient flooring materials over the building life

\footnotetext{
*Correspondence: Deborah Wingler, PhD, MSD-HHE, EDAC; Email: dwingle@g.clemson.edu; Address: Healing Design Integration, 332 Village Walk Ln. Clemson, SC 29631, United States.
} 
of an acute-care facility. The purpose of this study is to provide healthcare administrators, facility managers and designers with evidence regarding the total cost of ownership of different resilient flooring materials.

Evidence linking design features in the physical healthcare environment to patient and staff health outcomes show flooring can substantially contribute to patient and staff safety, health, and experience. ${ }^{[4,5]}$ Prior research conducted by Harris \& Detke ${ }^{[4]}$ suggests there is a relationship between flooring type (e.g. vinyl or carpet) and finish (e.g. high-gloss or matte) and injury related issues pertaining to patient and staff slips, trips and falls. Additionally, in their review of the literature, they identified flooring as a contributing factor to staff fatigue, environmental noise, and healthcare acquired infections (HAIs) ${ }^{[4]}$ Recent research suggests that hospital floors are a prevalent source of surface contamination, supporting the transmission of healthcare associated pathogens that can lead to HAIs. ${ }^{[6-8]}$ Cleaning and maintenance protocols, which are influenced by behavioral factors at both the individual and organizational level, are an integral component in a system of interventions for the prevention of HAIs. ${ }^{[9]}$

Resilient flooring has long been considered the predominate flooring material choice for high-traffic areas in healthcare environments due to its ease of maintenance, affordability, and durability. ${ }^{[3]}$ In response to health, wellness, and evidencebased design trends that have advocated for more sustainable healthcare environments that support an increased connection to nature for patients and staff, resilient flooring has advanced considerably in material composition beyond the traditional vinyl and linoleum products of the 1960s-1970s. ${ }^{[3]}$

Resilient flooring materials range in terms of the level and type of cleaning and maintenance required to retain the products aesthetic quality and functional integrity from products such as VCT that require stripping, coating, and refinishing over the product's entire usable life to provide additional layers of floor finish for aesthetic and preventative maintenance practices to products such as premium rubber that have no factory applied finish and never require coating or stripping to retain its aesthetic quality and functional integrity during its usable life. Not only does stripping, coating, and refinishing require more labor and time-intensive maintenance practices, prior research suggests that the use of heavy chemicals during the stripping and coating process exposes patients and staff to caustic solvents that can decrease patient and staff respiratory health. ${ }^{[10-12]}$

One of the central advances in material sciences has been the range of finish coatings that are now being applied to resilient flooring materials during the manufacturing process to enhance the wear surface. These protective, factory applied finishes are increasingly scratch and chemical resistant, and are being applied to resilient materials such as luxury vinyl tile (LVT), linoleum, and sheet vinyl. One of the main benefits to these protective coatings is that they are intended to reduce the need for maintenance protocols associated with stripping and coating. However, while resilient flooring materials with factory applied finishes do not require stripping, coating, and refinishing initially upon installation, it is feasible that the factory applied finish at some point during the products usable life will wear off depending on cleaning and maintenance regime, and level of foot traffic. ${ }^{[13]}$ Therefore, requiring either material replacement or initiating a costly maintenance protocol that necessitates stripping, coating, and refinishing to maintain aesthetic quality and sustain functional integrity for the remainder of the flooring material's usable life. ${ }^{[13]}$

Due to its low initial cost and wide selection of finishes, vinyl flooring (either VCT or sheet vinyl) currently covers the majority of floors in US healthcare facilities. ${ }^{[13]}$ However, with its factory applied coating, moderate pricing, and less institutional aesthetic alternatives, LVT is quickly becoming an increasingly popular choice of flooring material for healthcare facilities. ${ }^{[14,15]}$ With the majority of resilient flooring in U.S. healthcare facilities requiring a stripping, coating, and refinishing maintenance regimen at some point during its usable life, it is essential to understand the impact of their associated maintenance protocols on the total cost of ownership.

Over the last decade, several life-cycle assessments (LCAs) and risk assessments have been conducted comparing the environmental impact and potential health effects of various resilient flooring materials. ${ }^{[3,16,17]}$ While these studies provide an environmental accounting over the entire service life of different resilient flooring materials on ecological and human health, they largely neglect the impact of operations and maintenance during the use phase due to challenges in establishing assumptions that can account for uncertainty in maintenance practices. ${ }^{[17]}$

In contrast to LCA, life-cycle cost analysis (LCCA) provides a method for evaluating solely the economic impact of alternative materials with similar functional performance criteria but varying costs over the service life of a building or a building system. ${ }^{[18]}$ The LCCA method takes into account all costs associated with acquiring, operating, maintaining and disposing that vary between materials and can have a significant financial influence on the total cost of ownership. ${ }^{[18]}$

To date, a limited number of life-cycle costing studies for flooring have been conducted comparing hard, resilient, and 
soft flooring material systems in healthcare, ${ }^{[2]}$ educational, ${ }^{[1]}$ and residential ${ }^{[19]}$ environments. Findings from these studies suggest that flooring maintenance can have a significant impact on the total cost of ownership, and that the flooring material with the lowest initial cost did not always exhibit the lowest life-cycle cost. However, findings specific to resilient flooring materials have not been congruent between studies. Moussatche \& Languel ${ }^{[1]}$ found that, although VCT exhibited the lowest initial cost, linoleum exhibited the lowest life-cycle cost for the resilient flooring materials studied, while Harris \& Fitzgerald ${ }^{[2]}$ found a direct relationship between lowest initial cost and life-cycle costs for VCT.

Although both studies accounted for differences in maintenance protocols between flooring material systems (hard, resilient, and soft) the same basic maintenance protocol was applied to all resilient flooring types evaluated. For example, all resilient flooring types other than VCT evaluated in the study by Harris \& Fitzgerald ${ }^{[2]}$ were considered to have a urethane sealant, which implies a factory applied finish, negating the need for stripping, coating, and refinishing, and the labor costs associated with its maintenance protocol. However, due to material science advances in resilient flooring, not all resilient flooring materials require a factory applied sealant or the use of stripping and coating for aesthetics and preventative maintenance. Gunther \& Langowski ${ }^{[17]}$ suggest that these types of assumptions can "strongly effect the end result". Therefore, it is essential, that the varying material composition in relation to the required maintenance protocol be accounted for when evaluating life-cycle costs for similar flooring types within a system. Further challenging our understanding of the economic implications of maintenance protocols on the total cost of ownership for healthcare facilities is incongruent product information from manufacturers regarding service life and recommended maintenance regimes, as well as a lack of clearly defined industry maintenance standards. To provide a more accurate and relevant assessment of life-cycle costs that can support user decision making, Moussatche \& Languel ${ }^{[1]}$ advocate for the use of "real-time" data to frame LCCA assumptions.

\section{MethodS}

\subsection{Research design}

Utilizing a LCCA, a two-phase economic evaluation was conducted through two different means using industry and real-time data to evaluate the impact of coated and noncoated resilient flooring materials over the usable life of an acute-care facility. For the first phase, a traditional LCCA method was utilized to identify potential differences in lifecycle costs between coated and non-coated resilient flooring materials based on industry standard maintenance protocols for healthcare facilities. ${ }^{[18]}$

A multiple-case study embedded with multiple units of analysis was conducted for the second phase to evaluate the impact of actual operations and maintenance protocols in acute-care facilities on coated and non-coated resilient flooring materials. $^{[20]}$ Six acute-care facilities from four large health systems of varying geographic regions of the United States (U.S.) were selected for this study, allowing for possible differences in regional costs (e.g. installation, labor rates, and chemical costs) or the impact of organizational maintenance protocols on flooring material durability. Across the six acute-care facilities, 10 medical/surgical, two neonatal intensive care (NICU), and four labor and delivery inpatient units with different resilient flooring materials were evaluated.

\subsection{Data collection}

For this study, resilient flooring materials were categorized in terms of the level of maintenance required to retain the products aesthetic quality and functional integrity. Resilient flooring materials requiring the use of stripping, coating, and refinishing over their entire usable life to maintain the products innate material properties were categorized as coated. In contrast, resilient flooring materials never requiring the application of stripping, coating and refinishing to retain the products aesthetic quality and functional integrity during its usable life were categorized as non-coated. Resilient flooring materials with factory applied finishes were also categorized as non-coated, as initially during their usable life they do not require the use of stripping, coating, and refinishing to maintain the products innate material properties. However, at the juncture in its usable life when the factory applied coating no longer sustained, then the product was recategorized as coated. Product selection was based on typically specified coated and non-coated resilient flooring materials for healthcare facilities that met industry standards for maintenance, safety, infection control, and performance criteria. ${ }^{[21]}$

\subsubsection{Phase 1}

To provide a benchmark for potential life-cycle costs of coated and non-coated resilient flooring materials, industry data was acquired for the following product information: warranty, maintenance protocols and their associated man hours, installation requirements, and cost data. The R.S Means Cost Estimating database ${ }^{[22]}$ was used to acquire cost data pertaining to initial costs associated with material, installation, and overhead and profit (O\&P). Initial costs were further verified through third party industry reports and in the field.

Cost data for operations and maintenance (O\&M) was acquired from manufacturer specifications for type and fre- 
quency (daily, weekly, monthly and yearly) of recommended maintenance protocols for the resilient flooring materials evaluated. The amount of cleaning hours required to complete the associated maintenance protocols was established using the International Sanitation Supply Association (ISSA) 612 Cleaning Times \& Tasks standards. ${ }^{[23]}$ The ISSA's Cleaning Times \& Tasks is the leading industry publication for established standards regarding maintenance staff workloads. Labor rate for O\&M was established using Bureau of Labor statistics for general medical and surgical hospital janitor and cleaner services. ${ }^{[24]}$ As the ISSA labor data defines cleaning hours by square footage for patient rooms and hallways, the ratio of patient rooms to hallways was established for the first phase as $60 \%$ and $40 \%$, respectively, using the Space Planning Guide for Healthcare facilities. ${ }^{[25]}$ Equipment size for patient rooms was considered as 18 inches for mop and 20 inches for machine, while equipment size for hallways was considered as 30 inches for mop and 20 inches for machine. Cleaning supply costs pertaining to the type and dilution rate of required cleaning solutions for the recommended maintenance protocols was determined using manufacturer specifications, while costs associated with coverage of the cleaning supplies were determined using ISSA 612 Cleaning Times \& Tasks standards data. ${ }^{[23]}$

\subsubsection{Phase 2}

For the second phase, empirical data was collected from the six acute-care facilities evaluated using a questionnaire to provide a more accurate insight into the total cost of ownership by including the healthcare facilities' true maintenance costs and product longevity. Questionnaires were completed by the Director of Environmental Services of each facility. The questionnaire included data on the total unit area, percent of total unit area allocated to patient rooms and hallways, type and install cost of resilient flooring material in present value, type and frequency of current maintenance protocols (daily/weekly/monthly/annually), equipment size (mop and machine) for patient rooms and hallways, cost and dilution rate of cleaning supplies, labor costs (without benefits), and the number of finish coats applied to existing coated resilient materials.

\subsection{Data analysis}

\subsubsection{System parameters and assumptions}

The parameters and assumptions for both phases of the LCCA were defined in accordance with the National Institute of Standards and Technology (NIST) and Department of Energy (DOE) standards for conducting a LCCA. ${ }^{[26]}$ Analysis for both phases is based on cost per square foot (SF).

Building and system service life. The building service life for acute-care facilities is considered to be 50 years. ${ }^{[27]}$ The Published by Sciedu Press service life for each resilient flooring system alternative was established using the Resilient Floor Covering Institute's (RFCI) generic environmental product declarations (EPDs). These third-party verified reports include the environmental impacts, as well as expected service life in years, for the referenced resilient flooring, and are certified by UL Environment. ${ }^{[28]}$ The number of replacements was determined by the resilient flooring system's service life in respect to the building service life. For example, if a resilient flooring alternative's system service life is 25 years, one replacement would be required during the 50-year building life of an acute-care facility.

Flooring system. All resilient flooring materials evaluated for this LCCA are considered as exposed to heavy foot and equipment traffic.

Discount rate. When using the LCCA method, it is essential that initial costs, which include all costs to attain, install, and prepare the flooring material for occupancy, and all future costs associated with maintenance and system replacement incurred after occupancy be brought to a common reference point. To do so, a discount rate must be utilized to bring all future costs to present value, as it is assumed that the value of the dollar in the future will be greater than the present dollar value. ${ }^{[29,30]}$ For this LCCA the discount rate is a weighted average cost of capital, defined using two distinct interest rates for: 1) material and supplies and 2) labor. As resilient flooring materials and cleaning supply costs have historically experienced a $1.8 \%$ yearly increase in costs, their associated discount rate for future costs associated with material replacement and maintenance supplies was defined as the yearly inflation rate $(1.8 \%)$ plus $1 \%$ for a total of $2.8 \%$. For maintenance labor, the discount rate is defined as the prime interest rate $(4.25 \%)$ plus $1 \%$ for a total of $5.25 \%$. To express future value $(\mathrm{FV})$ in present value (PV) for material and supplies, the discount rate was utilized over the system life of each resilient flooring option (25, 30, or 35 years), while the FV for maintenance labor was calculated using the discount rate of $5.25 \%$ over the 50 -year building life. The FV of materials and supplies and labor were individually determined using the following equation (see Equation 1).

$$
F V=P V(1+r / n)^{t}
$$

Where $P V=$ present value (product or O\&M), $r=$ interest rate $(0.018$ or 0.0425$), n=100$, and $t=$ service life in years (system or building)

Salvage value. It is assumed for this LCCA that no salvage value exists, as the cost of each resilient flooring system alternative is considered to be fully expended over its system 
service life.

Equipment. Equipment costs were not included in this LCCA, as all resilient flooring materials evaluated require the same basic equipment (mop and machine) to support preventative maintenance. Price differences between alternative equipment options vary greatly due to size, functionality, and features, making associated cost differences reflective of organizational preference not flooring material type.

Initial costs. Initial costs included flooring material costs comprised of material, freight and prep work, installation costs associated with labor, adhesive and floor preparation and initial cleaning, and overhead and profit, and were determined using the following equation (see Equation 2):

$$
M+I+O \& P=\text { Total Initial Cost }(P V)
$$

Where $M=$ material costs, $I=$ installation costs, and $\mathrm{O} \& \mathrm{P}=$ overhead and profit

O\&M costs. Future costs associated with operations and maintenance costs included labor (total cleaning minutes per year per SF) and cleaning supply costs per SF. These costs were determined by the different resilient flooring materials' respective recommended maintenance protocol using the following equation (see Equation 3):

$$
L+S=\text { Total Operations and Maintenance }
$$

Where $L=$ labor costs and $S=$ cleaning supply costs

\section{Results}

\subsection{Phase 1}

The degree to which coated and non-coated maintenance protocols could potentially impact the total life-cycle costs of resilient flooring materials for acute-care facilities was first examined using a traditional LCCA method. The results from the first phase were used to provide a benchmark for findings from the second phase.

\section{Initial costs}

Initial costs were comprised of material and installation costs as outlined above, and overhead and profit (see Table 1). The lowest initial cost for the resilient flooring options examined was vinyl composition tile (VCT). Coated rubber, as well as linoleum, non-coated luxury vinyl tile (LVT), linoleum and sheet vinyl exhibited mid-range cost options, while premium rubber was found to be the most expensive. The system service life for each resilient flooring option, as determined by the RFCI generic environmental product declarations, is also shown in Table 1 . The system life for the resilient flooring options examined ranged from 25-35 years, requiring all coated and non-coated resilient flooring options to be replaced at least one time during the 50-year building service life.

\section{$3.20 \& M$}

To provide an accurate economic accounting of the costs associated with operations and maintenance, it is essential to clearly identify recommended manufacturer maintenance protocols, as these recommendations are intended to ensure product integrity and longevity. Manufacturer and industry recommended maintenance protocols for the resilient flooring options examined, along with their associated industry standard time to complete are outlined in Table 2. The least amount of cleaning minutes for tasks associated with the recommended protocols was associate with non-coated resilient flooring options, while those requiring a coating exhibited the greatest amount of time to complete the recommended tasks for heavy foot and equipment traffic.

\begin{tabular}{|c|c|c|c|c|c|c|c|}
\hline \multicolumn{2}{|c|}{ Material Type } & \multirow{2}{*}{$\begin{array}{l}\text { System Service } \\
\text { Life in Years } \\
25\end{array}$} & \multirow{2}{*}{$\begin{array}{l}\text { Unit } \\
\text { SF }\end{array}$} & \multirow{2}{*}{$\begin{array}{l}\begin{array}{l}\text { Material } \\
\text { Cost }\end{array} \\
\$ 1.77\end{array}$} & \multirow{2}{*}{$\begin{array}{l}\text { Install Cost } \\
\$ 0.75\end{array}$} & \multirow{2}{*}{$\begin{array}{l}\text { O\&P } \\
\$ 0.54\end{array}$} & \multirow{2}{*}{$\begin{array}{l}\begin{array}{l}\text { Total Initial } \\
\text { Cost }(\mathbf{P V})\end{array} \\
\$ 3.06\end{array}$} \\
\hline & $\mathrm{VCT}^{\mathrm{C}}$ & & & & & & \\
\hline tatua & Rubber ${ }^{\mathrm{C}}$ & 35 & SF & $\$ 3.59$ & $\$ 1.04$ & $\$ 0.86$ & $\$ 5.49$ \\
\hline \multirow{4}{*}{ Non-coated } & LVT $^{\mathrm{D}}$ & 30 & $\mathrm{SF}$ & $\$ 4.86$ & $\$ 1.04$ & $\$ 1.14$ & $\$ 7.04$ \\
\hline & Linoleum $^{\mathrm{D}}$ & 35 & SF & $\$ 3.59$ & $\$ 1.04$ & $\$ 0.86$ & $\$ 5.49$ \\
\hline & Sheet Vinyl ${ }^{\mathrm{D}}$ & 30 & SF & $\$ 4.22$ & $\$ 1.63$ & $\$ 1.20$ & $\$ 7.05$ \\
\hline & Premium rubber ${ }^{\mathrm{N}}$ & 35 & SF & $\$ 6.50$ & $\$ 1.04$ & $\$ 0.86$ & $\$ 8.40$ \\
\hline
\end{tabular}

Table 1. Initial cost of coated and non-coated resilient flooring materials

Note. ${ }^{\mathrm{C}}=$ requires coating per manufacturer recommendations during the material's entire usable life; ${ }^{\mathrm{D}}=$ requires coating to maintain appearance and integrity at some point during the material's usable life; ${ }^{\mathrm{N}}=$ never requires coating to maintain appearance and integrity during the material's usable life 
As the total system cost per SF increased from PV to FV, resilient flooring materials that required a coated maintenance protocol exhibited a greater increase in the percent of total system costs related to O\&M than non-coated resilient flooring materials (see Table 3). For example, VCT was found to have the highest percentage of total system costs related to $\mathrm{O} \& \mathrm{M}$, while premium rubber was found to have the lowest, with VCT exhibiting a $32 \%$ increase in O\&M as compared to premium rubber. Additionally, VCT exhibited a 22\%-27\% increase in percentage of total system costs related to O\&M as compared to LVT, linoleum, and sheet vinyl. Furthermore, coated rubber exhibited an 11\%-20\% increase in percentage of total systems costs relate to O\&M as compared to the non-coated resilient flooring materials. However, it should be noted that the total system costs in Table 3 reflect a FV for O\&M that assumes the wear layer for non-coated resilient flooring options with a factory applied coating does not wear off during the system service life of the product, potentially providing a conservative estimate of the actual total system cost for those flooring materials.

Table 2. Maintenance protocol for coated and non-coated resilient flooring materials for heavy traffic

\begin{tabular}{|c|c|c|c|c|c|c|c|c|c|}
\hline \multirow[b]{2}{*}{ Material Type } & & \multicolumn{3}{|c|}{ Dust Mop } & \multicolumn{2}{|c|}{ Damp Mop or Microfiber } & \multicolumn{3}{|c|}{ Auto Scrub } \\
\hline & & $\begin{array}{l}\text { Patient Room } \\
\text { 18” Microfiber }\end{array}$ & \multicolumn{2}{|l|}{$\begin{array}{l}\text { Hallway } \\
\text { 30" Microfiber }\end{array}$} & $\begin{array}{l}\text { Patient Room } \\
\text { Mop or 18" } \\
\text { Microfiber }\end{array}$ & Hallway & Patient Room & \multicolumn{2}{|c|}{$\begin{array}{l}\text { Hallway } \\
\text { 20" Machine w/ 30" } \\
\text { Microfiber }\end{array}$} \\
\hline \multirow{2}{*}{ Coated } & $\mathrm{VCT}^{\mathrm{C}}$ & Daily & Daily & \multicolumn{2}{|c|}{ Daily } & $\mathrm{n} / \mathrm{a}$ & $\mathrm{n} / \mathrm{a}$ & \multicolumn{2}{|l|}{ Daily } \\
\hline & Rubber ${ }^{\mathrm{C}}$ & Daily & Daily & \multicolumn{2}{|c|}{ Daily } & $\mathrm{n} / \mathrm{a}$ & $\mathrm{n} / \mathrm{a}$ & \multicolumn{2}{|l|}{ Daily } \\
\hline \multirow{4}{*}{ Non-coated } & $\mathrm{LVT}^{\mathrm{D}}$ & Daily & Daily & \multicolumn{2}{|c|}{ Daily } & $\mathrm{n} / \mathrm{a}$ & $\mathrm{n} / \mathrm{a}$ & \multicolumn{2}{|l|}{ Daily } \\
\hline & Linoleum $^{\mathrm{D}}$ & Daily & Daily & \multicolumn{2}{|c|}{ Daily } & $\mathrm{n} / \mathrm{a}$ & n/a & \multicolumn{2}{|l|}{ Daily } \\
\hline & Sheet Vinyl ${ }^{\mathrm{D}}$ & Daily & Daily & \multicolumn{2}{|c|}{ Daily } & $\mathrm{n} / \mathrm{a}$ & $\mathrm{n} / \mathrm{a}$ & \multicolumn{2}{|l|}{ Daily } \\
\hline & $\begin{array}{l}\text { Premium } \\
\text { Rubber }^{N}\end{array}$ & Daily & Daily & \multicolumn{2}{|c|}{ Daily } & $\mathrm{n} / \mathrm{a}$ & $\mathrm{n} / \mathrm{a}$ & \multicolumn{2}{|l|}{ Daily } \\
\hline \multirow{2}{*}{\multicolumn{2}{|c|}{ Material Type }} & \multicolumn{2}{|c|}{ Strip/6 Coats/Refinish } & \multicolumn{2}{|c|}{ Burnish } & \multicolumn{2}{|c|}{ Deep Scrub } & \multicolumn{2}{|c|}{$\begin{array}{c}\text { Total Cleaning } \\
\text { Minute/Year /SF }\end{array}$} \\
\hline & & $\begin{array}{l}\text { Patient Room } \\
18 \text { " Mop } \\
20 \text { " Machine }\end{array}$ & $\begin{array}{l}\text { Hallway } \\
\text { 30" Mop } \\
\text { 20" Machine }\end{array}$ & $\begin{array}{l}\text { Patient } \\
\text { Room }\end{array}$ & $\begin{array}{l}\text { Hallway } \\
\text { 20" Machine }\end{array}$ & $\begin{array}{l}\text { Patient Room } \\
\text { 20" Machine }\end{array}$ & $\begin{array}{l}\text { Hallway } \\
\text { 20" Machine }\end{array}$ & $\begin{array}{l}\text { Patient Room } \\
(60 \%)\end{array}$ & $\begin{array}{l}\text { Hallway } \\
(40 \%)\end{array}$ \\
\hline \multirow{2}{*}{ Coated } & $\mathrm{VCT}^{\mathrm{c}}$ & $2 \mathrm{x} / \mathrm{yr}$ & $1 \mathrm{x} / \mathrm{yr}$. & $1 \mathrm{x} /$ month & $3 \mathrm{x} /$ week & $\mathrm{n} / \mathrm{a}$ & $\mathrm{n} / \mathrm{a}$ & 7.42 & 6.35 \\
\hline & Rubber $^{\mathrm{C}}$ & $2 \mathrm{x} / \mathrm{yr}$. & 1x/yr. & $1 \mathrm{x} /$ month & $3 \mathrm{x} /$ week & $\mathrm{n} / \mathrm{a}$ & n/a & 7.42 & 6.35 \\
\hline \multirow{4}{*}{ Non-coated } & LVT $^{{ }^{D}}$ & $\mathrm{n} / \mathrm{a}$ & n/a & n/a & $\mathrm{n} / \mathrm{a}$ & $2 \mathrm{x} / \mathrm{yr}$. & $2 \mathrm{x} / \mathrm{yr}$ & 4.11 & 4.55 \\
\hline & Linoleum $^{\text {D }}$ & $\mathrm{n} / \mathrm{a}$ & $\mathrm{n} / \mathrm{a}$ & $\mathrm{n} / \mathrm{a}$ & $\mathrm{n} / \mathrm{a}$ & $2 \mathrm{x} / \mathrm{yr}$ & $2 \mathrm{x} / \mathrm{yr}$ & 4.11 & 4.55 \\
\hline & Sheet Vinyl ${ }^{\mathrm{D}}$ & $\mathrm{n} / \mathrm{a}$ & $\mathrm{n} / \mathrm{a}$ & $\mathrm{n} / \mathrm{a}$ & $\mathrm{n} / \mathrm{a}$ & $2 \mathrm{x} / \mathrm{yr}$ & $2 \mathrm{x} / \mathrm{yr}$ & 4.11 & 4.55 \\
\hline & $\begin{array}{l}\text { Premium } \\
\text { Rubber }\end{array}$ & $\mathrm{n} / \mathrm{a}$ & n/a & n/a & $\mathrm{n} / \mathrm{a}$ & $2 \mathrm{x} / \mathrm{yr}$ & $2 \mathrm{x} / \mathrm{yr}$. & 4.11 & 4.55 \\
\hline
\end{tabular}

Note: ${ }^{\mathrm{C}}=$ requires coating per manufacturer recommendations during the material's entire usable life; ${ }^{\mathrm{D}}=$ requires coating to maintain appearance and integrity at some point during the material's usable life ${ }^{\mathrm{N}}=$ never requires coating to maintain appearance and integrity during the material's usable life

\subsection{Phase 2}

To further demonstrate the impact of O\&M on the total cost of ownership for resilient flooring materials in acute-care facilities, analysis was conducted to examine differences in costs associated with coated and non-coated maintenance protocols on resilient flooring materials using real-time data from each case.

As shown in Table 4, the cases for this study represented three distinct geographic regions located in the Northeast, Midwest, and Southeast of the U.S. The health systems ranged in size from 500-1,000 beds to 2,000-2,500 beds, while labor costs without benefits ranged from $\$ 13.50$ - $\$ 19.00$ (without benefits) across cases. Supply costs associated with cleaner, stripper, and wax were the lowest at Case 2 and highest at Case 4, while Cases 1 and 3 exhibited mid-range supply costs.

\subsubsection{Initial costs}

Of the resilient flooring materials examined, the VCT in Case 3 and Case 4 exhibited the lowest initial costs. Across cases, LVT, sheet vinyl, and coated rubber were found to exhibit similar initial costs, while premium rubber was found to have the highest initial costs for all resilient flooring materials evaluated. 


\subsection{2 $O \& M$}

The total life-cycle costs for the resilient flooring materials evaluated within each case up through year 35 are shown in Figure 1. These costs reflect one material replacement for each resilient flooring type evaluated. When comparing the total life-cycle costs across cases, resilient flooring materials that required a coated maintenance protocol at any point in time during their usable life exhibited a higher total cost of ownership as compared to non-coated flooring materials within the same case. The same relationship was found for the percent of total system costs related to O\&M within each case (see Figure 1). For the remainder of the building service life, the same differences would be expected.

Table 3. Total system costs of resilient flooring materials based on present and future values

\begin{tabular}{|c|c|c|c|c|c|c|}
\hline \multicolumn{2}{|c|}{ Material Type } & $\begin{array}{l}\text { System Service } \\
\text { Life Years }\end{array}$ & $\begin{array}{l}\text { Number of } \\
\text { Replacements }\end{array}$ & Unit & $\begin{array}{l}\text { Total Initial } \\
\text { Cost }(\mathbf{P V})\end{array}$ & $\begin{array}{l}\text { Total O\&M } \\
\text { (PV) }\end{array}$ \\
\hline \multirow{2}{*}{ Coated } & $\mathrm{VCT}^{\mathrm{C}}$ & 25 & 1 & SF & $\$ 3.06$ & $\$ 3.69$ \\
\hline & Rubber $^{\mathrm{C}}$ & 35 & 1 & SF & $\$ 5.49$ & $\$ 3.69$ \\
\hline \multirow{4}{*}{ Non-coated } & $\operatorname{LVT}^{\mathrm{D}}$ & 30 & 1 & SF & $\$ 7.04$ & $\$ 2.20$ \\
\hline & Linoleum $^{\mathrm{D}}$ & 35 & 1 & SF & $\$ 5.49$ & $\$ 2.20$ \\
\hline & Sheet Vinyl ${ }^{\mathrm{D}}$ & 30 & 1 & SF & $\$ 7.05$ & $\$ 2.20$ \\
\hline & Premium Rubber ${ }^{N}$ & 35 & 1 & SF & $\$ 8.40$ & $\$ 2.20$ \\
\hline \multicolumn{2}{|c|}{ Material Type } & $\begin{array}{l}\text { Total System Cost } \\
\text { (PV) }\end{array}$ & $\begin{array}{l}\text { Total Replacement } \\
\text { Systems Cost (FV) }\end{array}$ & Total O\&M (FV) & $\begin{array}{c}\% \mathrm{O \& M} \text { of } \\
\text { system }(\mathrm{FV})\end{array}$ & $\begin{array}{l}\text { Total System } \\
\text { Cost (FV) }\end{array}$ \\
\hline \multirow{2}{*}{ Coated } & $\mathrm{VCT}^{\mathrm{C}}$ & $\$ 6.75$ & $\$ 4.78$ & $\$ 29.60$ & $71.97 \%$ & $\$ 41.13$ \\
\hline & Rubber $^{\mathrm{C}}$ & $\$ 9.18$ & $\$ 10.25$ & $\$ 29.60$ & $60.37 \%$ & $\$ 49.03$ \\
\hline \multirow{4}{*}{ Non-coated } & $\operatorname{LVT}^{\mathrm{D}}$ & $\$ 9.24$ & $\$ 12.03$ & $\$ 17.64$ & $45.34 \%$ & $\$ 38.91$ \\
\hline & Linoleum $^{\mathrm{D}}$ & $\$ 7.69$ & $\$ 10.25$ & $\$ 17.64$ & $49.58 \%$ & $\$ 35.58$ \\
\hline & Sheet Vinyl ${ }^{\mathrm{D}}$ & $\$ 9.25$ & $\$ 12.04$ & $\$ 17.64$ & $45.31 \%$ & $\$ 38.93$ \\
\hline & Premium Rubber ${ }^{N}$ & $\$ 10.60$ & $\$ 15.68$ & $\$ 17.64$ & $40.16 \%$ & $\$ 43.92$ \\
\hline
\end{tabular}

Note ${ }^{\mathrm{C}}=$ requires coating per manufacturer recommendations during the material's entire usable life; ${ }^{\mathrm{D}}=$ requires coating to maintain appearance and integrity at some point during the material's usable life; ${ }^{\mathrm{N}}=$ never requires coating to maintain appearance and integrity during the material's usable life

Table 4. Case context for resilient materials examined

\begin{tabular}{lllllll}
\hline \multirow{2}{*}{ Case } & \multirow{2}{*}{ Region } & \multirow{2}{*}{ Number of Beds } & \multirow{2}{*}{ Labor Cost/Hour } & \multicolumn{3}{c}{ Supply Costs/Gallon } \\
\cline { 5 - 6 } & & & Cleaner & Stripper & Wax \\
\hline 1 & Midwest & $1,000-1,500$ & $\$ 13.89$ & $\$ 44.00$ & $\$ 14.00$ & $\$ 11.25$ \\
2 & Northeast & $500-1,000$ & $\$ 14.50$ & $\$ 21.00$ & $\$ 18.75$ & $\$ 19.75$ \\
3 & Southeast & $2,000-2,500$ & $\$ 13.50$ & $\$ 13.00$ & $\$ 58.93$ & $\$ 14.91$ \\
4 & Northeast & $500-1,000$ & $\$ 19.00$ & $\$ 97.00$ & $\$ 66.00$ & $\$ 14.12$ \\
\hline
\end{tabular}

The greatest difference between total life-cycle costs and percent of total system costs related to O\&M was found between the VCT and non-coated resilient flooring materials in Case 3 and Case 4, with VCT exhibiting between an 18\%-27\% and $19 \%$ increase in O\&M, respectively, as compared to the non-coated flooring materials evaluated from the same case. Similarly, Case 1 and Case 3 saw a substantial difference between the percent of total system costs related to O\&M, with flooring materials other than VCT that required a coated maintenance protocol exhibiting a 10\%-16\% and $10 \%-21 \%$ increase in O\&M, respectively, as compared to non-coated resilient flooring materials from the same case. However, a 76 lesser difference was found between the percent of total system costs related to O\&M for coated and non-coated resilient flooring materials in Case 2 and Case 4. Coated flooring materials in Case 2 exhibited an $8 \%-10 \%$ increase in the percent of total system costs related to O\&M as compared to non-coated flooring materials, while only a 6\%-8\% increase was found in Case 4. Furthermore, flooring materials with a factory applied finish that failed prior to replacement exhibited similar increases in total life-cycle costs and percent of total system costs related to O\&M as coated materials from the same case. 


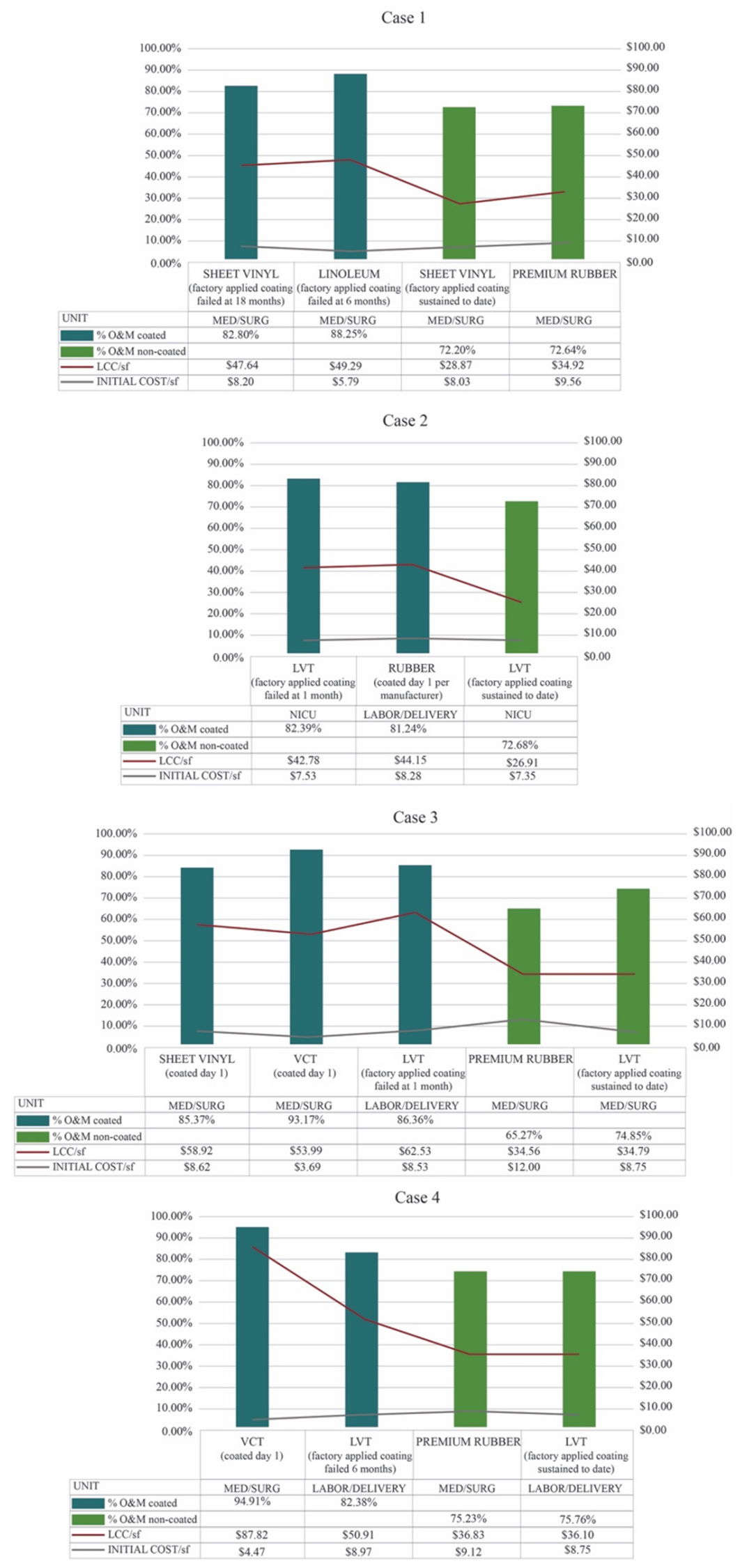

Figure 1. Initila costs, total life-cycle costs, and percent O\&M of resilient flooring materials in each inpatient unit evaluated 


\section{DiscuSSION}

Findings from both the first and second phase LCCA suggest that maintenance protocols can have a substantive impact on the total cost of ownership for resilient flooring materials due to the increase in O\&M costs associated with a coated maintenance protocol. Furthermore, these findings suggest O\&M costs are a direct indicator of total life-cycle costs, while initial costs are only an indicator for resilient flooring materials that utilize a similar maintenance protocol over their entire usable life.

Results from the first phase LCCA provided a somewhat inflated economic accounting of the differences between coated and non-coated flooring materials, compared to the results from the second phase. This difference can largely be attributed to the fact that the first phase used data based on industry standards that does not reflect variations in labor and supply costs, as well as preferred maintenance standards which differ across healthcare organizations. Additionally, the first phase did not reflect variations in product longevity for resilient flooring materials with a factory applied finish. The differences between the findings from the two approaches highlight the importance of integrating realtime data into a systematic evaluation to support informed decision-making and ensure material selection will best meet a healthcare organization's flooring needs.

Of the four cases examined, two cases exhibited substantial differences between the total cost of ownership between coated and non-coated flooring materials, while two cases saw moderate differences. One factor that can contribute to a reduction in cost savings associated with a non-coated maintenance protocol is the insertion of burnishing into the maintenance process. While manufacturer warranties and industry standards do not require burnishing to maintain a non-coated resilient flooring material's aesthetic quality and functional integrity (see Table 2), many healthcare organizations choose to insert burnishing into their maintenance protocol to increase gloss level. For this LCCA, two of the cases examined inserted burnishing into the non-coated maintenance protocol to support executive preference for an increased gloss level, reducing their amount of savings obtained.

Another factor that can contribute to differences between life-cycle costs of coated and non-coated resilient flooring materials are the costs associated with stripping and the number of coats reapplied to coated materials, and the man hours associated with the process. While industry standards recommend between 4-6 coats of wax to be utilized in a coated maintenance protocol (see Table 2), the actual number of coats reapplied can vary greatly across healthcare organi- zations based on executive leadership preference, infection control practices, financial drivers and historical organizational maintenance practices. Of the four cases examined in this study, once stripped the number of coats reapplied varied across cases from 1-4 coats. When implemented in multiple facilities across an organization, these variations in a coated maintenance protocol can greatly contribute to an increase or reduction in total life-cycle costs.

The point in time at which the factory applied finish failed for a non-coated flooring material was also shown to greatly contribute to the total cost of ownership. Several of the noncoated resilient flooring materials examined in this study were found to have their factory applied finish fail in under two years. Some failed within the first month. At the juncture in time when the factory applied finish failed, the healthcare organizations were required to switch to a more costly coated maintenance protocol to ensure the product retained its aesthetic quality and functional integrity. The life-cycle costs for these flooring materials were between 10\%-16\% higher per SF than similar flooring materials within the same case where the factory applied coating had sustained through the time of the study (see Figure 1). As such, resilient flooring materials that did not require the use of a coated protocol in this study exhibited the lowest life-cycle costs of the materials evaluated.

\section{Conclusions}

This two phase LCCA provides evidence that maintenance protocols associated with coated and non-coated resilient flooring materials can substantially impact the total cost of ownership per SF over the lifetime of an acute-care facility. The use of real-time data, coupled with a systematic evaluation provided contextual information that proved essential to understanding some of the intricacies involved in resilient flooring maintenance protocols that can greatly influence economic outcomes. This approach supports an evidencebased decision making process for healthcare executives and environmental services staff to not only effectively evaluate new resilient flooring material selections, but to also proactively evaluate current maintenance protocols for increased monetary savings.

While it is crucial to understand the economic implications when selecting resilient flooring materials for a healthcare facility, it is also essential to consider non-monetary benefits when making a final investment decision. Each resilient flooring material has its own distinct environmental implications and set of unique performance characteristics due to its material composition and the manufacturing process. Incorporating an environmental accounting into a LCCA and using an analytical hierarchy process ${ }^{[18]}$ to determine which 
performance characteristics best align with organizational objectives can further support more holistic decision-making.

\section{Limitations}

Limitations to this study are largely due to the time-sensitive nature of a cross-sectional study. Cost Data was captured during the first quarters in 2018 and may not reflect future economic conditions. Additionally, further technological innovations may have occurred in the composition of the flooring materials represented in this study that could enhance product longevity, aesthetic quality, and functional integrity since the time the materials were distributed and installed in the facilities examined. Furthermore, while it was imperative for this study to establish the service life for each resilient flooring system alternative using industry standards, many factors can contribute to a reduced service life for a flooring material, further impacting the total cost of ownership. Longiudinal evidence is needed to further understand the impact of maintenance protocols on the service life of resilient flooring materials. It is also important to note that improper maintenance can undermine the aesthetic quality and functional integrity of any resilient flooring material. To mitigate this limitation, on-site observations were conducted prior to data collection to ensure all flooring materials evaluated for this study received proper maintenance prior to data collection. Finally, the real-time data is geographically restricted to three distinct regions in the U.S. Further research is needed to examine congruence of findings across healthcare organizations in other geographic regions.

\section{ACKNOWLEDGements}

The author would like to acknowledge the health systems who participated in this study for providing the real-time cost data; R.S Means for providing initial cost data; and industry partners, ISSA, and product manufacturers for providing O\&M protocols and standards for this study.

\section{CONFlicts OF InTEREST Disclosure}

The author declares they have no conflicts of interest.

\section{REFERENCES}

[1] Moussatche H, Languel J. Life cycle costing of interior materials for Florida's schools. Journal of Interior Design. 2002; 28(2): 37-49. https ://doi.org/10.1111/j.1939-1668.2002.tb00377.x

[2] Harris DD, Fitzgerald L. A life-cycle cost analysis for flooring materials for healthcare facilities. Journal of Hospital Administration. 2015; 4(4): 92. https://doi .org/10.5430/jha.v4n4p92

[3] Lent T, Silas J, Vallette J. Chemical hazards analysis of resilient flooring for healthcare. HERD: Health Environments Research \& Design Journal. 2010; 3(2): 97-117. PMid: 21165873. https: //doi.org/10.1177/193758671000300209

[4] Harris DD, Detke LA. The role of flooring as a design element affecting patient and healthcare worker safety. HERD: Health Environments Research \& Design Journal. 2013; 6(3): 95-119. https : //doi.org/10.1177/193758671300600308

[5] Ulrich RS, Zimring C, Zhu X, et al. A review of the research literature on evidence-based healthcare design. HERD: Health Environments Research \& Design Journal. 2008; 1(3): 61-125. PMid: 21161908. https ://doi.org/10.1177/193758670800100306

[6] Deshpande A, Cadnum JL, Fertelli D, et al. Are hospital floors an underappreciated reservoir for transmission of health care-associated pathogens? American Journal of Infection Control. 2017; 45(3): 336-338. PMid: 28254251. https ://doi.org/10.1016/j.ajic .2016 .11 .005

[7] Koganti S, Alhmidi H, Tomas ME, et al. Evaluation of hospital floors as a potential source of pathogen dissemination using a nonpathogenic virus as a surrogate marker. Infection Control \& Hospital Epidemiology. 2016; 37(11): 1374-1377. PMid: 27523489. https://doi.org/10.1017/ice.2016.181

[8] Mahida N, Boswell T. Non-slip socks: a potential reservoir for transmitting multidrug-resistant organisms in hospitals? Journal of Hospital Infection. 2016; 94(3): 273-275. PMid: 27380919. https://doi.org/10.1016/j.jhin.2016.06.018
[9] Lenfestey NF, Denham ME, Hall KK, et al. Expert opinions on the role of facility design in the acquisition and prevention of healthcareassociated infections. HERD: Health Environments Research \& Design Journal. 2013; 7(1_suppl): 31-45. https ://doi .org/10.117 7/193758671300701S05

[10] Arif AA, Delclos GL. Association between cleaning-related chemicals and work-related asthma and asthma symptoms among healthcare professionals. Occup Environ Med. 2012; 69(1): 35-40. PMid: 21602538. https://doi.org/10.1136/oem. 2011.064865

[11] Arif AA, Delclos GL, Serra C. Occupational exposures and asthma among nursing professionals. Occupational and Environmental Medicine. 2009. PMid: 19164328.

[12] Quinn MM, Henneberger PK, Braun B, et al. Cleaning and disinfecting environmental surfaces in health care: toward an integrated framework for infection and occupational illness prevention. American Journal of Infection Control. 2015; 43(5): 424-434. PMid: 25792102. https://doi.org/10.1016/j.ajic. 2015.01.029

[13] Leafblad B. Floor-savviness for environmental services: How to maximize effectiveness while minimizing down time. Explore. 2015; 22-25.

[14] Floor Covering News. Scoring flooring: Industry stats for 2016. 2017. Available from: https://www.fcnews.net/2017/07/scoring -flooring-industry-stats-for-2016/

[15] Floor Covering Weekly. Statistical report 2016. 2017. Available from: https://mailchi.mp/hearst/fcw-daily-updat e-july-28-2017

[16] Altshuler K, Horst S, Malin N, et al. Assessment of the technical basis for a PVC-related materials credit for LEED. US Green Building Council. 2007.

[17] Günther A, Langowski HC. Life cycle assessment study on resilient floor coverings. The International Journal of Life Cycle Assessment. 1997; 2(2): 73-80. https://doi.org/10.1007/BF02978763 
[18] Fuller S. Life-cycle cost analysis (LCCA). 2016. Available from: http://www.wbdg.org/resources/life-cycle-cos t-analysis-lcca

[19] Minne E, Crittenden JC. Impact of maintenance on life cycle impact and cost assessment for residential flooring options. The International Journal of Life Cycle Assessment. 2015; 20(1): 36-45. https://doi.org/10.1007/s11367-014-0809-z

[20] Yin RK. Case study research and applications: Design and methods. Sage publications. 2014.

[21] FGI. Guidelines for Design and Construction of Hospitals and Outpatient Facilities. The Facility Guidelines Institute: St. Louis, MO; 2018.

[22] RS Means Cost Estimating, Reed Construction Data, Editor. Norwell: MA; 2018

[23] Walker B. The Official ISSA 612 Cleaning Times \& Tasks. Northbrook, IL. ISSA. 2014.
[24] Bureau of Labor Statistics. Occupational employment statistics. 2017. Available from: https://www.bls.gov/oes/current/oes 372 012.htm

[25] Hayward C. SpaceMed Guide: A space planning guide for healthcare facilities. Ann Arbor, MI. HA Ventures. 2015.

[26] NIST Annual Supplement to NIST Handbook 1365 (NISTIR) 853273-32.

[27] Carr R. Health care facilities. 2017. Available from: https://www . wbdg.org/building-types/health-care-facilities

[28] Resilient Floor Covering Institute (RFCI). Environmental Product Declaration. 2017. Available from: http://rfci.com/environ mental-product-declaration/

[29] Fuller S, Petersen S. Life-cycle costing manual for the federal energy management program, NIST Handbook 135 (No. Handbook (NIST HB)-135). 1996.

[30] Lavappa PD, Kneifel JD. Energy Price Indices and Discount Factors for Life-Cycle Cost Analysis-2016. 2016. 